\title{
EL NACIMIENTO DE LA HISTORIA JURÍDICA Y SU CONTRAPOSICIÓN CON LA DOGMÁTICA PANDECTÍSTICA
}

\author{
MARGARITA FUENTESECA DEGENEFFE \\ Pro. Titular de Derecho Romano \\ Universidad de Vigo
}

La Escuela Histórica viene a ser, como González Vicén afirma un positivismo historicista. Frente al iusnaturalismo la Escuela Histórica afirma

1 Como bibliografía más importante sobre este capítulo podemos citar: ARNOLD, F., y HARTMANN, M., Geisteswissenschaft und Naturwissenschaft Tübingen, Mohr, 1955. BADER, Y., S., Aufgaben und Methoden des Rechtshistorikers Mohr, Túbingen, 1951. BEKKER, E., Vier Pandektisten Heidelberg, Carl Winter Universitätsbuchhandlug, 1903. BIONDI, B., Universalitá a perennitá della Giurisprudenza romana en L'Europa e il Diritto romano (Studi in onore P. Koschaker), vol II, Milán, Giuffré, 1954. BONFANTE, P., La giurisprudenza nello svolgimento del Diritto Scritti IV, Roma 1925. Id. II metodo, naturalistico nella storia del Diritto, Scritti IV, Roma 1925; Id. L'autonomia della scienza del Diritto e i confini della filosofia, Scritti IV, 1925. BRETONE, M., La logica del giuristi di Roma Labeo 1 (1955), 74-8, BRUCK F. E., Römisches Recht und Rechtsproblem der Gegenwart, 1930. DE CASTRO Y BRAVO, F., La ciencia libre del derecho ies fuente primaria del Derecho?_en Anuario de Derecho Civil (1948), pp. 565-80. DULCKEIT, G., Philosofie der Rechtsgeschichte Quelle-Meyer, Heidelberg, 1950. D'ORS, A., De la prudentia iuris a la Jurisprudencia del TS en Información Jurídica, $\mathrm{n}^{\circ} 55$ (1947), pp. 63-82. FUENTESECA, P., Historia y Dogmática en la jurisprudencia europea en Rev de Derecho Notarial, $n^{\circ} 11$, (1956), p. 183-204. GARCÍA-GALLO, Historia, Derecho e Historia del Derecho en AHDE, XXIII, (1953, pp.5-36). GENZMER, E., II Diritto romano como fattore della civiltá europea en Conferenze Romanistiche, Universitá di Trieste, 1954. IHERING R, Geist des römischen Rechts auf den verschiedenen Stufen seiner Entwick Leipzig, 1923,11, 2, p. 357 ss. KOSCHAKER, P., Europa und das Römische Recht Biederstein, 1947 (ahora versión española de Santa Cruz Tejeiro). Id. Die Krise des römischen Rechts und die romanistische Rechtswissenschaft Schriften der Akademie für deutsches Recht, Munich, Beck, 1939. U. von LÜBTOW, Reflexionen über Sein und Werden in der Rechtsgeschichte, Berlín, Duncker-Humblot, 1954. METTEH, J., lus civile in artem redactum, Ruprecht, Göttingen 1954. MITTEIS H., Vom Lebenswert der Rechtsgeschichte Weimar, Böhlaus Nachfolger, 1947. Id. Die Rechtsgeschichte und das Problem der historischen Kontinuität Berlín, 1948. Id. Historismus und Rechtsgeschichte Festgabe Kauffmann Stuttgart-Köln, 1950, 268 ss. MOLITOR, E., Der Versuch einer Neukodification des römischen Rechts durch den Philosofen Leibiniz en L'Europa e il Diritto romano (Studi in memoria di P.Koschaker), vol I, p. 359-373. ORESTANO, R., Introduzione allo studio storico del Diritto romano Torino, Giapicelli, 1953. PLACHY, A., Il Diritto romano come valore culturale nella storia dell'Eropa (Studi in memoria di P. Koschaker) vol. I., p. 479-91. PUCHTA, Betrachtungen über alte und neue Systeme Rheinisches Museum 3, (1829). RICCOBONO, S., Vom Schicksal des römischen Rechts en Studia Humanitatis (Festschrift zur Eröffhung des Institutes), Berlín 1942. SCHWARZ, A., Pandektenwissenschaft und heutiges romanistisches Studium, Zurich 1928. WIEAKER, F., Privatrechtgeschichte der Neuzeit Götttingen, Ruprecht, 1952; Id. Friedrich Karl von Savigny en ZSS, 72, 
que el Derecho es, como el Arte o la cultura en general, un producto del espíritu del pueblo ${ }^{2}$.

Savigny no es un mero continuador del historicismo del XVIII, sino, el innovador genial que va a prestar sentido y fundamento al derecho positivo desde una nueva metafísica de la historia ${ }^{3}$. Savigny mantiene que cada época labora siempre en comunidad indisoluble con todo el pasado. El pueblo como unidad espiritual, es el sustrato y el sujeto de la historia, el punto último de referencia del mundo de formas de la vida nacional, como son religión, arte, usos populares, idioma, Derecho, constitución política. Todas ellas hunden sus raíces en el espíritu del pueblo.

La oposición de Savigny a la idea de la ley (o del derecho) como precepto del poder político es clara. Así la Escuela Histórica se nos presenta como antitética frente al positivismo legalista. Por eso Savigny se opone a la codificación en su célebre polémica con Thibaut. La idea codificadora había florecido ya en Prusia (1794), en Francia (C.c. 1804) y en Austria (1811).

Frente al iusnaturalismo racionalista Savigny mantiene que no hay un Derecho universal descubrible por la razón, ni hay, en rigor, siquiera un derecho; todo derecho es derecho de un pueblo, íntimamente unido a su individualidad ${ }^{4}$. Así la fuente de la normatividad no es la especulación racional sino, por primera vez, la facticidad histórica, como G. Vicén advierte 5. El Derecho no «es», sino que «llega a ser» y en este llegar a ser a lo largo del acontecer histórico se encuentra, no sólo el fundamento de su existencia, sino su justificación absoluta, su validez y su realidad ${ }^{6}$. Si para el racionalismo especulativo la realidad de cada momento era algo transitorio, punto sólo de arranque para un futuro conformado según las exigencias de la razón, para la burguesía conservadora el presente posee un valor absoluto. Esta concepción del derecho hunde sus raíces en la estructura social y en la voluntad histórica de la burguesía triunfante de la Restauración, que vive la realidad histórica viendo el presen-

(1955), p. 1-38. Id. Aufstieg, Blüte und Krise der Kodificationsidee, en Festschrift für G. Boehmer, Bonn, Röhrscheid, 1954, p. 34-50. Id. Über Aktualisierung und Ausbildunje im römischen Recht, en L'Europa e il Diritto romano (Studi in memoria di P. Koschaker), vol I, Milán, Giuffré, 1954, pp. 515-41.

2 GONZÁlEZ VICEN, F., Sobre el positivismo jurídico, Separata de los Estudios en Homenaje al profesor Giménez Fernández, Facultad de Derecho, Sevilla, 1967.

3 GONZÁLEZ VICEN, F., op. cit. p. 8.

4 GONZÁLEZ VICEN, F., op. cit. p. 10.

5 GONZÁLEZ VICEN, F., op. cit. p. 11.

6 GONZÁLEZ VICEN, F., op. cit. 
te desde el pasado, como su presencia y su culminación. Tal es el supuesto ideológico sobre el cual se alza la teoría del Derecho de la Escuela Histórica 7.

La Escuela Histórica aporta al positivismo (del cual es una rama historicista) la idea de que el derecho es una ordenación real y concreta en el tiempo o como decía Savigny, que el derecho es la vida misma de los hombres vista de un lado especial 8 . Esta concepción del derecho como fenómeno histórico-social propia del positivismo produce un enfrentamiento con un principio metódico fundamental de los siglos modernos: la escisión del universo jurídico en dos esferas herméticas e incomunicables entre sí la esfera de la pura normatividad y la esfera fáctica y amorfa del acontecer social. Así con gran convicción ha visto G. Vicén la grave escisión metódica que va a dar lugar al florecer de la historia por un lado y de la dogmática por otro ${ }^{9}$. De estas dos esferas --dice G. Vicén- sólo una, la esfera de la normatividad es en sentido estricto objeto de la ciencia del derecho, mientras que la facticidad social sólo es susceptible de un conocimiento empírico situado, por definición, más allá de las fronteras de la ciencia jurídica. El derecho en tanto que objeto de conocimiento científico no es entendido desde el mundo social ni referido a él sino como un conjunto abstracto de proposiciones unidas entre sí por relaciones de carácter lógico ${ }^{10}$. Bajo el influjo de la ciencia natural matemática el Derecho natural del racionalismo va a construir el mundo del Derecho como un sistema de normas abstractas de conducta, cuyo carácter jurídico y cuya validez descansan en sus conexiones formales recíprocas y en la posibilidad de su referencia a una proposición axiomática fundamental

Se pretendía crear una ciencia del Derecho concibiendo éste con validez absoluta y universal. Este derecho sería el único (además de ser el «verdadero derecho») que podría ser objeto de conocimiento científico en sentido riguroso. Esta metodología sobrevivía al Derecho natural y gravita como un dogma sobre la ciencia del dere-

7 Vid. cita en GONZÁLEZ VICÉN, op. cit. p. 25.

8 Vid. GONZÁLEZ VICÉN, op. cit. p. 25.

9 Vid. sobre la escisión entre la Historia y la dogmática, FUENTESECA, P., Historia y dogmática en la jurisprudencia europea, en Rev. de Derecho Notarial, $\mathrm{n}^{\circ} 11,1956$, p. 183 : «Una de las mayores dificultades que tiene planteadas la Jurisprudencia europea actual, en cuanto tarea científica, es el divorcio entre Dogmática e Historia. Los estudios jurídicos se nos presentan bajo dos facetas cada vez más alejadas entre sí. Una de éstas mira al cultivo del Derecho como conjunto de normas y principios que regulan la vida jurídica actual, recogidos y presentados con un criterio sistemático que aspira a ser válido con rigor científico. A los ojos de gran parte de los juristas actuales en esto parece consistir la verdadera ciencia jurídica. La otra faceta de los estudios jurídicos consiste en investigar el Derecho histórico a través de las fuentes de la época correspondiente, haciendo con ello historia del Derecho. En esta dirección, los estudios jurídicos se han acercado cada a vez más, como era inevitable, a las ciencias históricas en cuanto a método y fines. La historia del Derecho tiene por objeto la realidad histórica (sein) mientras el cultivo dogmático del Derecho intenta establecer principios válidos para la vida jurídica actual (sollen) deducidos del orden vigente»

10 Vid. GONZÁLEZ VICÉN, F. op. cit. p. 25. 
cho contemporánea. Este método geométrico -que ya Grocio había postulado como modelo para la ciencia jurídica- imprime su sello, no solamente en la jurisprudencia conceptual, sino que se convierte en el ideal declarado de los teóricos del neokantismo " y alcanza su expresión clásica en la geometría de los fenómenos jurídicos de KeIsen, con su reducción del derecho a un sistema de conceptos estrictamente formales y la referencia de su validez a una norma fundamental postulada.

Desde la Escuela Histórica se comprende el punto de partida de las dos grandes ramas de la historia jurídica europea: el Derecho romano (la historia del mismo cada vez más como disciplina histórica) y la Historia del Derecho Germánico ${ }^{12}$. Ambas ramas del saber histórico-jurídico comenzaron a cultivarse cada vez más como disciplinas rigurosamente históricas. Los métodos de las ciencias históricas se les aplican cada día con mayor rigor; en primer lugar la depuración de fuentes.

La corriente historicista de la Escuela Histórica deja en marcha el estudio del ser histórico del Derecho. Y el hecho más curioso dentro del pensamiento y la obra de Savigny es la actualización del Derecho romano, que él investiga sin riguroso criterio histórico, imposible en su momento, como demuestra su famosa monografía sobre la possessio romana ${ }^{13}$. Pero este hecho de dedicarse con todo ahínco al estudio del Derecho romano y de colocar a sus discípulos en las cátedras de Derecho romano parece ser un tanto contradictorio con la idea de que el derecho nace del espíritu del pueblo. Claro que Savigny traiaba de actualizar el Derecho romano para aplicarlo a su época, como prueba su Tratado de Derecho romano actual; pero, en todo caso, no era un derecho germánico el que Savigny postulaba e imponía en nombre del Volksgeist (espíritu del pueblo).

Al lado de los estudios histórico-jurídicos, cada vez más cercanos a las ciencias históricas, aparece después de la Escuela Histórica la concepción derivada del usus modernus pandectarum señalando como ideal de ciencia el de las ciencias naturales basadas en leyes de rigor universal. La idea de ciencia se dirige por el camino de la

\section{Vid. GONZÁLEZ VICÉN, F., op. cit. p. 25}

12 Vid. FUENTESECA, P., Historia y dogmática op. cit, p. 188: «La Escuela Histórica que fue, en cuanto movimiento intelectual, la mayor revolución en orden a las concepciones jurídicas que se han operado en Europa, hizo caer los postulados de la concepción racionalista de un Derecho absoluto al sentar la idea de historicidad de éste en cuanto producto concreto de la voluntad popular. El gran acierto que significó el reivindicar la historicidad del Derecho no fue, naturalmente, debido exclusivamente a la genialidad de los principales representantes de aquélla (con haber sido mucha su originalidad creadora) sino al conjunto de factores que el Romanticismo trajo consigo: la reivindicación de lo concreto y particular frente a las abstracciones lógicas, la interpretación psicológica de los hechos morales en su individualidad histórica, etc. Quizá no se haya dicho todavía la última palabra acerca del significado de esta Escuela, pero en el aspecto que ahora nos interesa puede decirse que con ella nace la Historia del Derecho como disciplina aparte.»

13 Vid. SAVIGNY, F.C. Das Recht des Besitzes, $1^{\text {a }}$ ed. Berlín, 1803; $7^{\text {a }}$ ed. Berlín 1964; ed. fototípica Darmstadt 1967. 
construcción dogmática o sistema de conceptos abstractos concatenados lógicamente. Es la llamada jurisprudencia de conceptos (Begriffsjurisprudenz) o como dice Wieacker, positivismo científico, una especie de derecho profesoral (Professorenrecht) ${ }^{14}$.

Pero acaso la mayor originalidad de la Escuela Histórica consiste en haber hecho compatible una tendencia histórica con otra sistemática. Método histórico y método sistemático se integran, de modo que el primero debe conducir al conocimiento científico del derecho, mientras el segundo permite realizar aquel conocimiento ordenado por principios en que se concreta el ideal de ciencia que Kant había dado. La tendencia sistemática de la Escuela Histórica nada tiene que ver ya con las construcciones dogmáticas de la dirección racionalista en las cuales se procedía por vía de deducción de principios, abstracta y apriorísticamente establecidos, a la construcción del sistema. La más alta expresión de estas ideas se halla en Puchta, el cual afirmaba en su difundido Cursus der Institutionen ${ }^{15}$ que la ciencia del derecho tiene dos lados, el sistemático y el histórico. La sistemática que la Escuela Histórica propugna, más que una construcción operada por la ciencia, es el descubrimiento de un orden estructural inscrito en la realidad misma del Derecho concebido como organismo ${ }^{16}$.

A pesar de sus postulados teóricos el paso de la tradición expositiva se impuso y Savigny y su escuela siguen el sistema elaborado por Thibaut y Heise. Savigny pone dicho sistema como fundamento de su mejor obra: System des heutigen römischen Rechts. Todos los secuaces de la Escuela Histórica siguen la sistemática trazada y el mismo Savigny llega a reconocer que no hay inconciliabilidad absoluta entre las tendencias anteriores y la suya. De este acercamiento nace la Pandectística alemana del

14 Sobre el Professorenrecht vid. también KOSCHAKER P. Europa und das römische Recht, 4. Auflage, München-Berlin, 1966. p. 211 sig: considera conveniente utilizar el término «derecho de juristas» (Juristenrecht para el derecho de los prácticos, frente al «derecho de los profesores» (Professorenrecht); este último aparece cuando en un tiempo determinado y bajo ciertas circunstancias adquiere mayor peso el estudio del Derecho en las Universidades, enseñado por los profesores. Esto no quiere decir, según Koschaker, que sean los profesores los que creen y contribuyan al desarrollo del Derecho, sino que el Juristenrecht y el Professorenrecht pueden coexistitir, aunque con el tiempo suele prevalecer el profesor del derecho frente al práctico. Este autor se apoya en el ejemplo del Derecho romano tardío, el cual, a pesar de su método casuístico, era «derecho de profesores», puesto que los juristas más eminentes son los profesores de derecho.

15 Vid. PUCHTA, Cursus der Institutionen, $8^{\mathrm{a}}$ ed. Krüger, Leipzig, 1875, p. 56. Id. Betrachtungen über alte und neue Systeme_Rheinisches Museum 3 (1829).

16 Cfr. ORESTANO, Introduzione allo studio storico del diritto romano, Torino, Giapicelli, 1953, p. 25. Id: Introduzione allo studio del diritto romano ed. 11 Mulino, Bolonia 1987. Sobre esta obra de Orestano, vid. FUENTESECA, P., Historia y dogmátic op. cit. , p. 183, nota a pie: «Este libro de Orestano constituye una valiosísima aportación al tema candente de la validez de los estudios históricos en el campo del Derecho. Orestano es, como se sabe, un destacado romanista que ha investigado con fina sensibilidad de historiador y jurista sobre diversos institutos romanos; domina, por tanto, la técnica de la investigación histórica. Pero, desde su puesto de romanista ha sentido la preocupación, hoy común, de la razón de ser de sus propios estudios, de la validez, en una palabra, del Derecho romano en la actualidad.» 
siglo XIX, que es histórica en el modo de considerar la naturaleza y formación del derecho, y sistemática, esto es, generalizadora y tendente a la abstracción en el procedimiento constructivo ${ }^{17}$. Pero el estudio sistemático al alejarse de la Escuela Histórica tomó direcciones procedentes en parte de la ancestral raíz del racionalismo, naturalista que condujeron a extremos inaceptables contra los cuales reaccionó lhering 18 enérgicamente 19.

El cultivo histórico del derecho tiene su más esplendorosa manifestación en el campo del Derecho romano a fines del siglo pasado y en el actual. La Pandectística, como hemos dicho, significó un usus modernus pandectarum, esto es, una utilización de la más importante fuente del Derecho romano, el Digesto o Pandectas compilado bajo el emperador Justiniano, extrayendo de este vasto conglomerado de pensamiento jurídico las ideas y concepciones romanas para exponerlas en un esquema organizado según la sistemática que ya el mismo Savigny habla elegido.

Esta sistemática aceptada por Savigny y admitida en general por la Pandectística consiste en la siguiente distribución de la materia jurídica: 1.-Parte general; 2.Derechos Reales; 3.- Obligaciones; 4.- Derecho de Familia; 5.-Derecho Hereditario (Savigny coloca en esta última parte la in integrum restitutio, como medio para resolver las relaciones jurídicas de cualquier naturaleza).

Esta nueva sistemática expositiva que se convirtió en normal entre los pandectistas es el resultado de una larga evolución y, sobre todo de un cambio de conceptos del pensamiento jurídico europeo, en relación sobre todo del Derecho romano. Veamos en breve resumen lo ocurrido, que es sumamente importante como cambio

17 Cfr. ORESTANO, op. cit. p. 26.

18 Vid. IHERING, Historia y Dogmática p. 100. Otras obras: Geist des römischen Rechts au den verschiedenen Stufen seiner Entwicklung (1852). Según FUENTESECA, P., Historia y Dogmática... op. cit. p. 191: En esta obra, «una de las creaciones más brillantes de Ihering y de la ciencia romanística del siglo pasado, aparece claramente su propósito de ir más allá de los datos positivos del Derecho romano para alcanzar el sentido profundo, el espíritu del pensamiento jurídico romano. Pero donde señala la ley finalística como norma orientadora tanto de la investigación histórica como de la elaboración científica es en su famosa obra de la edad madura: Der Zweck im Recht (El fin en el Derecho), de la cual el volumen primero fue publicado en $1877 \mathrm{y}$ el segundo en 1884.»

19 Vid. FUENTESECA, P., Historia y Dogmática..., op. cit, p. 190: « Se llegó a considerar la sistemática como perfectible en sí misma, como un puro orden de formas lógicas del Derecho aplicables a cualquier contenido. Los conceptos mediante los cuales se operaban las construcciones sistemáticas venían así a adquirir valor absoluto hasta que negaron a perder el contacto con la realidad. El gran mérito de Ihering consiste en haber percibido esta situación y haberse enfrentado con ella decididamente. A pesar de haber sido discípulo de los más excelentes representantes de la Escuela Histórica -amigo y admirador de Puchta- todos sus esfuerzos están dirigidos a superar la que denominó Begriffjurisprudenz. Ihering reprocha a esta "Jurisprudencia de conceptos" el hecho de haberse alejado de la realidad y finalidad del Derecho. De ahí que el fin práctico sea el motor de toda su concepción. Así como el mundo físico se halla regido por la ley de la causalidad, así el mundo moral, social y jurídico sería regido por la ley de la finalidad. El fin es el verdadero creador del Derecho y tanto la investigación histórica como la elaboración científica deben estar orientadas por esta ley finalística». 
de perspectiva en el pensamiento jurídico europeo. Lo ocurrido, efectivamente, es trascendente y no se operó en unos días: se trata, en el fondo, de que el Derecho romano había dejado poco a poco de ser la fuente normativa por excelencia -hecho que ocurría en la Edad Media- para convertirse en fuente histórica. Veamos las líneas o etapas generales de este cambio que podría verse como el paso o el cambio de la Edad Media a la Moderna europea en el pensamiento jurídico.

La Edad Media desde el Renacimiento jurídico del siglo XI, había mirado al Derecho romano, concretamente al Digesto, como una fuente dogmática del saber jurídico. En el Digesto estaba contenido el Derecho por excelencia, algo así como la verdad jurídica o el saber jurídico indiscutible. El jurista medieval -los glosadores y comentaristas- veían en el Digesto el libro del saber jurídico. El paralelo entre la actitud de los juristas y de los teólogos es claro, como Koschaker ${ }^{20}$ recuerda acertadamente: el Digesto era para los juristas como la Biblia para los teólogos. Ambos libros constituían fuentes dogmáticas -de acuerdo con el estilo cultural de la Edad Mediarespecto a las cuales cabían glosas y comentarios, pero siempre con carácter de interpretación del texto que había que respetar como exponente de la verdad jurídica o teológica. Los Juristas se formaban especialmente en Bolonia donde Irnerius, un magister que enseñaba Artes, comenzó a leer el Digesto y enseñarlo. Como el Derecho tenía una trascendencia política indudable, los emperadores protegieron los estudios de Bolonia, del mismo modo que los Papas protegieron los estudios teológicos de París. De estos dos grandes focos universitarios irradian los dos tipos de saberes más importantes del universo cultural de la Edad Media: los estudios jurídicos y los estudios teológico-filosóficos. Bolonia fue un centro de formación de juristas y París lo fue de teólogos y filósofos. El método de estudio y la actitud ante las fuentes era análoga, como hemos dicho. A los emperadores les interesaba el cultivo del Derecho romano en cuanto se trataba de un Derecho Imperial; era el Derecho del Imperio romano que desde Carlomagno había sido restaurado en Europa. Pero además este Derecho del Imperio colocaba al emperador en la cumbre del poder político.

No se concebía al Derecho romano sin el emperador como figura cumbre de la organización política, parte de que en algunos principios jurídicos romanos el absolutismo imperial había quedado definido para siempre con expresiones: princeps legibus solutus est, quod principi placuit, legis habet vigorem...

Considerando el Derecho como un saber dogmático la actitud del jurista ante los textos romanos del Digesto fue primero la de glosadores o clarificadores del los textos y más tarde de comentaristas. Estos actuaron con más soltura frente al pensamiento jurídico romano comentando los textos con mayor libertad de criterio. Pero el texto romano seguía siendo la verdad jurídica inalterable y susceptible solamente de interpretación. De ahí que el comentario siguiese el orden del Digesto, un orden de comentario legal, como se ha denominado. Los comentarios seguían el orden del

Vid. KOSCHAKER, P. Europa ... op. cit. p.62, 
texto legal comentado igual que ocurría con el comentario al texto de los Libros Sagrados. El escolasticismo y el criterio de autoridad propio de la Edad Media no es ajeno a este tipo de sistemática vinculada al orden legal o del texto comentado. La última expresión de este método o sistema puede verse en los célebres Erläuterung der Pandekten (Comentarios a las Pandectas) de Glück, cuya publicación se inició en 1789-90 y fue realizado por él hasta el libro XXVII (Tit. 1).

La desviación respecto al texto justinianeo, con intento de crear una nueva sistemática, no se dio claramente hasta la Escuela Culta francesa del siglo XVI, cuyo fruto es el primer gran tratado sistemático de la Edad Moderna: los 28 Libri Iuris Civilis de Doneau. Naturalmente fue preciso un cambio de mentalidad provocado por el Renacimiento y la superación del dogmatismo inherente a los saberes medievales. El Renacimiento humanista provocó la crítica de los textos jurídicos romanos desde el punto de vista filológico y entonces se delataron las primeras interpolaciones de los mismos. El Digesto dejó de ser una fuente dogmática e indiscutible y el saber jurídico se hizo perfectible. Considerado por primera vez desde siglos el Digesto como un libro jurídico histórico por los humanistas juristas, se abrió camino una ordenación sistemática ajena al orden sistemático del Digesto mismo. Así se abrió paso la sistemática de Doneau y más tarde los tratados sistemáticos de Domat y Pothier que constituyeron la nervatura del Código de Napoleón. Pero entre los Humanistas y estos últimos tratados sistemáticos franceses median las corrientes iusnaturalistas de tipo racionalista que impulsaron a aludida sistemática en su afán de crear un gran edificio racional de conceptos jurídicos válidos en todo tiempo y lugar. Así pretendían, como se sabe, crear una ciencia jurídica bajo el modelo de las llamadas ciencias naturales.

Doneau había dado un gran paso, pero la idea no cundió inmediatamente. La preocupación por una nueva sistemática expositiva de la materia jurídica preocupó al mismo Leibniz en su Nova methodus discendae jurisprudentiae ex artis didacticas principiis (1667). La exposición y sistemática expositiva era mirada como un nuevo método porque en el fondo implicaba una concepción nueva de la materia misma sistematizada: era una forma seu methodus iuris disponendi. Leibniz volvió sobre el tema en 1668 en su escrito Ratio corporis iuras reconcinnendi. Desde entonces se llamaron reconcinnatores los que se alejan de las formas tradicionales para buscar nuevas formas de exposición sistemática (también se llaman methodices). Poco tiempo después, en 1757, apareció un escrito de Pütter titulado Entwurf einer juristischen Enzyclopädie, en que se propugnaba el abandono de un orden legal en el estudio de las Pandectas y su sustitución por un libre orden sistemático. La innovación halló contradictores y todavía Hugo, el iniciador de la Escuela Histórica, después de hacer profesión de fe en la sistemática, acabó recomendando el orden legal. Fue más bien la llamada Escuela Filosófica la que dio el impulso hacia la sistemática, sobre todo por su máximo representante que fue Thibaut, el cual reajustó su System des Pandekten rechts en sucesivas ediciones, atendiéndose al sistema expositivo de Heise. El sistema de éste consistía en las siguientes partes: 1.-Parte general; 2.-Derechos Reales; 3.-Obligaciones; 4.-Derecho de Familia; 5.-Derecho hereditario; 
6.- In integrum restitutio. Este es el sistema que luego aceptó Savigny después de haber polemizado con Thibaut a propósito del tema de la codificación en Alemania. Y en general los Pandectistas, como hemos dicho, adoptaron esta sistemática que el Derecho Civil ha seguido, en líneas generales pero sobre todo en España. Cuando la nueva sistematización se impuso existía ya una nueva concepción del Derecho y habían comenzado las codificaciones (Prusia 1794; Austria 1811) pero entre ellas el gran modelo fue el Código de Napoleón (1804). Estas dieron vida de nuevo a la forma exegética realizada mediante comentarios que seguían el orden legal y así floreció en Francia, por ejemplo, la denominada «Escuela de la Exégesis», basando esta labor exegética en el Código de Napoleón. Y asimismo sobre los nuevos códigos se desarrolló una nueva literatura de carácter sistemático que tomó como modelo los criterios de la Pandectística. La forma de estudio sistemático se convierte en predominante y se extiende desde el Derecho Privado -en que antes había tenido su marco exclusivoa todas las ramas jurídicas. Casi llegaron a identificarse conocimiento sistemático y ciencia del Derecho y lo que fue forma disponendi pasó a ser así principio teórico y cognoscitivo. Como elemento impulsor de esta identificación actuó la idea difundida por la Escuela Histórica de que la sistemática era un elemento intrínseco del Derecho, no una construcción arbitraria lógicamente determinada. La sistemática se convirtió en un elemento interno del Derecho, una especie de dato objetivo que la ciencia debía traer a la luz y descubrir. Mediante la sistemática la ciencia del derecho realizaba a la vez su propia tarea y su cientificidad.

Pero el estudio sistemático, alejado ya de la Escuela Histórica e impulsado por el racionalismo iusnaturalista, tomó impulso tal que sus construcciones llegaron a denominarse «Jurisprudencia de conceptos». Se llegó a considerar la sistemática como perfectible en sí misma, como un orden de formas lógicas del Derecho aplicables a cualquier contenido. Los conceptos mediante los cuales se operaban las construcciones sistemáticas venían así a adquirir valor absoluto al margen de la realidad.

Mientras este conceptualismo daba lugar a un saber jurídico ajeno a la realidad, en nombre del cual Ihering ${ }^{21}$ levantó las invectivas más duras y su nueva idea de Jurisprudencia de intereses, los estudios históricos en el marco del Derecho Romano Germánico se desarrollaban con toda pujanza acercándose en sus métodos cada vez más a las ciencias históricas. Los pandectistas querían construir la ciencia del derecho con su sistema de conceptos lógicos encadenados con pretensión de validez uni-

21. Según FUENTESECA, P., Historia y Dogmática, , op. cit. p. 191; Thering no ataca el conceptualismo como tal sino sus exageraciones, la abstracción a que había llegado la Pandectística, e incluso algún jurista romano, como Paulo, a quien critica también en sus conocidos estudios sobre la posesión. Ihering pretende fundar la mejor técnica científica en la elaboración de conceptos. Esta rigurosa formulación conceptual tenía como meta la construcción de un sistema orgánico denominado «Dogmática». Precisamente en 1857 fundó Ihering la revista titulada: «Jahrbücher für die Dogmatik des heutigen römischen und deutschen Privatrechts» La divisa de la nueva dirección era: a través del Derecho romano pero más allá del Derecho romano. 
versal. Los historiadores del Derecho, en cambio, buscaban la cientificidad por el camino de los métodos históricos, depurando las fuentes y tratando de descubrir los más puros estratos de la evolución jurídica histórica. En el terreno de las investigaciones de Derecho romano a fines del siglo surgieron las grandes figuras del romanismo crítico. Lenel reconstruyó el Edicto del Pretor e hizo la Palingenesia Iuris Civilis. Gradenwitz puso de manifiesto la gran cantidad de interpolaciones del Digesto y así comenzó la difusión del nuevo método histórico-crítico en el campo del Derecho romano. Como además, después de la promulgación en 1900 del Código Civil alemán el Derecho romano había dejado de ser fuente vigente en Alemania, se miraron cada vez más las fuentes romanas, en especial el Digesto, como fuentes históricas susceptibles de depuración y no como fuentes normativas de derecho vigente.

El estudioso del Derecho romano se convirtió así en investigador de un Derecho histórico y el método histórico-crítico pareció el alma nueva destinada a descubrimos un nuevo Derecho romano más puro bajo las alteraciones impuestas por los compiladores justinianeos. Una gran ilusión se extendió entre los estudiosos del Derecho romano al aplicar el nuevo método, que iba a descubrir un derecho clásico más puro debajo del caparazón justinianeo. En efecto, las interpolaciones o alteraciones de los textos existían y el descubrirlas significaba una original e intrépida tarea científica que llegó a verse como la «caza de la interpolación». Como en todo método, surgieron las exageraciones de los hipercríticos, que veían alteraciones o interpolaciones en todos los textos del Digesto. El método se convirtió para algunos en un medio o arma fácil de esgrimir para probar cualquier teoría y pocos romanistas de la primera mitad de nuestro siglo escaparon a la seducción de la crítica interpolacionista como método para sostener nuevos puntos de vista pretendidamente clásicos. Se admitió en los primeros decenios de nuestro siglo que un cierto carácter bizantino habla teñido o coloreado el Derecho romano compilado por Justiniano. Dada la gran cantidad de alteraciones y la pujanza de las Escuelas de Derecho de Berito y Constantinopla, se llegó a admitir la existencia de un derecho más bien romano-bizantino, base de la compilación. En los últimos decenios sin embargo, ha cambiado la valoración de las alteraciones existentes en los textos justinianeos. En primer lugar se han descubierto alteraciones prejustinianeas y, por otra parte, se ha podido comprobar que los escritos de los juristas romanos han sido objeto de una labor de copia al instaurarse el codex como forma de transmisión de las obras escritas en vez del liber. Entonces, a partir del siglo III, numerosas obras fueron objeto de alteraciones y especialmente las obras de los juristas que, debido a esta reelaboración, llegarían ya alteradas a manos de los compiladores.

Hoy no se admite una tan vasta labor reelaboradora de los compiladores y la crítica de interpolaciones como método de investigación de las fuentes romanas ha perdido actualidad y una parte de su vigor. Las alteraciones pueden proceder de muy diverso origen, por una parte, y no se puede tampoco, por otra parte, admitir como existentes los millares de interpolaciones recogidas en el Index Interpolationum. Pocos pasajes del Digesto quedarían inmunes a la mano alteradora si hacemos caso 
a las miles de presuntas interpolaciones señaladas en más de tres cuartos de siglo de activa investigación romanística.

La crisis del método interpolacionista y el alejamiento entre los estudiosos del Derecho romano y los civilistas modernos -rama la civilística surgida de las fuentes romanas en su contenido fundamental- hizo aparecer voces de alarma y entre los romanistas se habló de crisis del Derecho romano y hasta de la necesidad de actualizar nuestros estudios como, para señalar un ejemplo insigne, hizo Paul Koschaker. Este propugnaba la Aktualisierung 22 del Derecho romano, una actualización que no distanciase a romanistas y juristas modernos. Pero esta actualización resulta difícil y el divorcio entre romanistas y juristas actuales se sigue percibiendo, especialmente en países como España, donde la formación en Derecho romano de los estudiosos no se ha caracterizado por su intensidad. No ocurre lo mismo en Italia donde el jurista se forma universitariamente a lo largo de tres cursos de Derecho romano e incluso en Alemania donde, asimismo, el Derecho romano se estudia en las Universidades, superado el paréntesis nazi.

Para la formación del iusprivatista el estudio del Derecho romano a fondo resulta imprescindible si quiere operar con conocimiento de causa, o lo que es lo mismo, con conocimiento histórico respecto al pasado de las instituciones jurídico-privadas. La mayor parte de los preceptos contenidos en Códigos europeos y la problemática del Derecho privado en Europa occidental solamente se comprende partiendo de Roma.

Pero aparte de esta razón hay que tener además en cuenta, que la formación histórica es la única que puede dar asiento riguroso al saber jurídico. No se trata ya que el derecho es producto de una facticidad social como la Escuela Histórica ha propugnado, sino que la legislación de cada momento está condicionada en mayor o menor medida por el pasado tanto inmediato como mediato. La ley, como dijo von Lübtow ${ }^{23}$, el que fue ilustre romanista berlinés, no cae del cielo como un meteorito sino que tiene un pasado histórico que la condiciona. Ciertamente la legislación, incluso en los países donde se ha legislado motorizadamente, arrastra una

22 Vid. KOSCHAKER, P. Europa... op. cit. p. 344 ss, 365 ss: «Aktualisierung des Studiums des römischen Rechts». Vid. también WIEACKER, F., Über Aktualisierung der Ausbildung im römischen Recht, en L'Europa e il Diritto romano, Studi in memoria di P. Koschaker, vol I, Milán, Giuffré, 1954, p. 515-541.

23 Vid. VON LÜBTOW, Reflexionen über Sein und Werden in der Rechtsgeschichte, Berlín, Dunker-Humblot, 1954. 
vinculación al pasado al que quiere modificar o superar en cuanto la ley opera sobre la sociedad siempre en evolución.

La formación histórica equivale a la verdadera formación científica del jurista. La historia jurídica -en general la historia del Derecho- puede dar al jurista una formación esencial, que es la historia de la experiencia jurídica, como no hace mucho tiempo señaló Orestano preocupado por el papel de la historia Jurídica en general y del Derecho romano en particular. La ciencia jurídica vendría a identificarse con la historia de la experiencia jurídica.

El saber jurídico para apoyarse en una fundamentación causal rigurosa ha de ser, en primer lugar un saber histórico-jurídico en el sentido más amplio. No solamente debe conocer el jurista cómo se ha desenvuelto el derecho en Roma y en la Edad Media sino en el pasado más inmediato y próximo al derecho vigente. En este sentido es muy interesante para el jurista el conocer, no ya las ideas iusprivatistas que desde Roma penetraron en los códigos europeos occidentales y concretamente en el español, sino también la formación o proceso de elaboración que ha conducido a estos códigos. Un jurista español debe conocer el Derecho romano como el acervo jurídico fundamental de Europa y además la evolución que ha conducido al Código Civil español, que constituye el Derecho civil vigente en España. De este modo comprenderá nuestro Código Civil desde el plano superior de sus causas y de su historia y no como una cristalización definitiva de nuestro derecho. Percibirá claramente el jurista así formado que los códigos son un episodio en la larga historia jurídica de Europa: son el producto final de la formación del Estado moderno, que sin duda darán paso algún día a una nueva legislación iusprivatista de ámbito europeo en la Europa unida del futuro, cuando apunte la idea de un superestado europeo como fórmula política hacia el cual caminamos por imperativo del progreso histórico.

Se ha olvidado demasiado la vinculación del Derecho a la idea política, sin detenerse los juristas a pensar que el progreso histórico -los retrocesos son mera apariencia- de la sociedad ha ido imponiendo nuevas formas jurídico-políticas porque el derecho es la nervatura de toda sociedad política. Por un lado el derecho es resultado de la evolución socio-económica y por otro es el ideal -en cuanto normatividad- en que se expresan los anhelos de la comunidad política (su punto de vista sobre la justicia). Sin perjuicio de volver sobre este tema que denominamos politicidad o condicionamiento político del derecho, queremos dejar sentada la idea de vinculación entre Derecho y Política o lo que es lo mismo, Derecho y Estado. A lo largo de toda la historia europea, desde Grecia, con la creación de la polis, las manifestaciones de la vida jurídica aparecen vinculadas a las formas políticas, mejor dicho, a la naturaleza del poder político. Así el Derecho medieval europeo refleja en el ius commune la idea unitaria del poder imperial como poder político más o menos efectivo, pero imperante como idea política sostenedora de la imperatividad de dicho ius commune, en una atmósfera de tensión frente a los núcleos de poder más modestos, que esgrimían su ius propium. Cuando surge el 
Estado moderno va abriéndose paso en el concepto de Estado la noción de un poder legislativo, que queda configurado desde Montesquieu y la Revolución francesa. Hobbes, teórico del absolutismo político luchará en Inglaterra frente al Derecho común inglés -Common Law- en cuanto se consideraba derecho preexistente al Estado e independiente de éste. Hobbes, a su vez, en su obra Diálogo entre un filósofo y un estudioso del Derecho común en Inglaterra, afirma: «No es la sabiduría sino la autoridad lo que crea la ley». He aquí la idea del Derecho como fruto de una voluntad soberana y no de la mera razón. Para Hobbes el derecho es producto de quien detenta el poder y por ello él niega valor al Common Law, que es resultado de la sabiduría de los jueces. 